\section{Kortikobasale Degeneration}

Helga Peter

Marburg, Deutschland

\section{Synonyme}

\section{CBD}

\section{Englischer Begriff}

corticobasal degeneration

\section{Definition}

Neurodegenerative Erkrankung; zählt zu den sogenannten Parkinson-plus-Syndromen.

Siehe $\triangleright$ „Parkinson-Syndrome“. 